\title{
Erratum to: Geochemical and environmental baseline of major and trace elements in Zarand coals, southeastern Iran
}

\author{
Alijan Aftabi · Seyed Vahid Shojaei • \\ Reza Kazerani Nezhad
}

Published online: 5 March 2015

(c) Springer-Verlag Berlin Heidelberg 2015

\section{Erratum to: Environ Earth Sci}

\section{DOI 10.1007/s12665-014-3919-9}

The authors would like to correct the errors in the original publication as detailed below.

The hyphen between major and trace was accidentally missed during the layout process in Abstract and Introduction. The correct form should be "major-trace" or "major and trace".

The year after Brookins in section "Chromium" has been missed in the final manuscript. The correct date should be Brookins (1990).

The online version of the original article can be found under doi:10.1007/s12665-014-3919-9.

A. Aftabi $(\bowtie) \cdot$ S. V. Shojaei

Department of Geology, Shahid Bahonar University of Kerman,

P.O. Box 76169-133, Kerman, Iran

e-mail: aftabi@mail.uk.ac.ir

R. K. Nezhad

Kerman Exploration Coal Company, Kerman, Iran 